lectures on specific problems in spinal lesions and rehabilitation. In the course of this programme we also train physiotherapists, occupational therapists and, above all, nursing staff. Refresher courses may take one to three days, while more comprehensive training courses take three to four months. Candidates for a doctor's degree are working in smaller groups when investigating special problems of paraplegia. Through scientific congresses and by advanced training courses for physicians and surgeons we are trying to collect and widen our experiences in this particular subject of medicine.

We seek, as other specialists do, close co-operation with other branches of medicine which are involved in the treatment of paraplegics and tetraplegics. In order to achieve such a close relationship we are going to organise interdisciplinary lectures to stimulate the exchange of experiences with other branches of medicine.

Another field of importance to which we give much attention is documentation and collecting of material dealing with rehabilitation as a special medical problem. In this respect we have established contact with other paraplegic units to pool experience on both medical and social problems.

One day when discussing rehabilitation problems with a well-known professor and director of a large university hospital, he expressed concern that a rehabilitation centre for paraplegics of the size of the Heidelberg centre might, like a hydrocephalus, disturb the organisational equilibrium of a hospital. While I can understand his concern, I cannot accept this view at all. I believe that a rehabilitation centre of this size may certainly become an important section of a large hospital and it may even become an integral part of the whole medical faculty of a university and may, by its initiative and work, exert a beneficial influence on other sections of the hospital and medical faculty as a whole. While such a specialised centre needs the co-operation and facilities of other specialities, its own facilities and the specialised knowledge of its staff can be of considerable benefit to other departments and thus make its contribution to the work of the hospital and medical faculty as a whole.

Let me conclude with a statement Lindemann made in I965: 'If we want to further and promote the concept and ideas of rehabilitation, and if we want to develop all measures serving the cause of rehabilitation, then science will have to deal with rehabilitation, and thus rehabilitation will become a subject of university research and teaching.'

\title{
THE MIDLAND SPINAL INJURY UNIT AT THE ROBERT JONES AND AGNES HUNT ORTHOPAEDIC HOSPITAL, OSWESTRY
}

\author{
By Terence McSweeney, M.Ch.(N.U.I.), M.Ch.(Orth.), F.R.C.S.(Eng.) \\ South Cheshire Hospital and the Robert Fones and Agnes Hunt \\ Orthopaedic Hospital, Oswestry
}

Assuming that our Continental colleagues may not be familiar with the Robert Jones and Agnes Hunt Orthopaedic Hospital, I thought I should begin with a brief historical account of the hospital. 
The hospital was founded in 1900 at Baschurch in Shropshire and moved to its present site in 1920. From then until I948 it was known as the Shropshire Orthopaedic Hospital. Its present title commemorates the guiding spirit of Sir Robert Jones and Dame Agnes Hunt.

It is still a long-stay country hospital in the traditional sense. The 450 beds are occupied by orthopaedic patients exclusively, but the emphasis today is on acute trauma, the late results of injury, the congenital and acquired musculoskeletal disorders, and the degenerative joint diseases, rather than on poliomyelitis and tuberculosis.

I think it is fair to say that the orientation of the hospital has always been towards the more difficult orthopaedic problems so that the designation of 64 beds as a spinal unit presented a challenge but no unfamiliar problem.

Our nursing staff were accustomed to the management of spinal tuberculosis, the neuro-muscular diseases and related problems. Griffiths and Roaf (I956) were able to report a series of 53 cases of Pott's paraplegia treated by antero-lateral decompression at Oswestry over the previous few years. Prior to 1962, spinal injuries were treated on an individual basis by the I 6 surgeons represented by four surgical teams. About this time a tendency developed towards the segregation of spinal injury patients into one or two wards. The patients remained under the care of their particular surgeon. Over the years, however, certain surgeons had shown a special interest in spinal surgery as a sub-speciality. Osmond-Clarke had inherited the scoliosis clinic from McCrae Aitken and found a willing scholar in Robert Roaf. Professor Roaf's life-long interest in this fascinating problem lead to many important discoveries in the mechanism of spinal deformities and interference with cord function which, bearing his published work in mind, needs no elaboration from me. Other surgeons had tackled equally intransigent aspects of spinal surgery.

In 1954 the Birmingham Regional Hospital Board suggested to the Management Committee that a scheme should be prepared for the treatment of 20 to 30 traumatic paraplegics in the hospital. Unfortunately no capital scheme materialised.

During I963 my colleagues on the Medical Advisory Committee recommended that a special unit was necessary and allocated 64 beds for this purpose. I was invited to take over this project which had the full support of the Management Committee and the Regional Board.

The population served was to include the traditional clinical area of the hospital and the large contributions of the Midlands-hence the designation 'Midlands Spinal Injury Centre'. In addition our consultant staff with attachments as far apart as the London Hospital-the Liverpool Royal Infirmary and the Manchester Royal Infirmary were welcome to send their paraplegic patients to the Unit.

The two wards set aside for this purpose were built in the traditional manner of orthopaedic wards. They were hopelessly inadequate in toilet facilities and in up-patient living space. We have made some progress in this direction by widening doors and redesigning and increasing the number of lavatories. Much remains to be done, particularly on the female ward.

The social worker and the secretary are accommodated on the ward. Case notes and X-rays in current use are kept on the unit. All case-notes are typed, 
and the parent copy together with clinical photographs, X-rays, etc., are kept in the main Records Department of the hospital. The fact that all the wards are single-storey buildings connected with a main service corridor has obvious advantages. The traditional Oswestry bed is mobile so that even before the wheelchair stage is reached the patient can be moved into the open air. There are obvious disadvantages in replanning wards designed for other purposes, and it would be an interesting exercise in economics to contrast this with a custom-built unit.

Apart from road and rail facilities, the siting of the hospital is such that our sports field offers excellent facilities for helicopters.

With regard to nursing staff, the fact that we have been designated a separate unit within the hospital has made an immense improvement in staff stability. Our senior nursing personnel have not changed since the unit started. They feel that they are very much part of a specialised 'set up', a point which has been emphasised to me again and again by Sir Ludwig Guttmann. The same remarks equally apply to the senior physiotherapists, the social worker and the occupational therapists.

Like every other hospital we have difficulties with junior nursing staff shortages. We are very fortunate in having a Nurse Training Centre and a programme whereby the junior nurse spends some of her time on the unit. We are particularly short of orderlies and see no ready solution to this. Voluntary helpers have made a great contribution to recreational activities, meal times and so on.

The hospital schoolteachers have been immensely helpful and have entered this new field of adult education with great enthusiasm. The Art instructor has been especially helpful with tetraplegic patients.

The senior physiotherapists are occupied for the most part in the management of the acute cases. Later the patients receive treatment in the general physiotherapy department but are still the responsibility of the unit physiotherapists.

A new swimming pool is used to great advantage.

Occupational therapy is well catered for-but we feel that more might be done on the wards in the early stages. Our intention is to re-design the Department this year and to include electronic, mechanical and engineering workshops on factory lines.

Taking a lesson from Stoke Mandeville, we have developed sport and recreational facilities to include archery, table tennis, bowls, and weight lifting.

On the professional side our staff include visiting general physicians, a neurologist, anaesthetists interested in respiratory problems, and a psychiatrist. Nevertheless, I felt we were lacking someone with a medical as distinct from an orthopaedic background who would be available in the unit every day. Acutely conscious of my own inadequacy in this aspect, I sought someone who would act as guide, philosopher and friend, not only to the patients, but who would be immediately accessible to the staff on the unit, and who would correlate the activities of the other disciplines. I secretly hoped then for a man with a postgraduate degree in general medicine who would be prepared to accept this responsibility. We were fortunate indeed in the appointment of Dr. Francis Jones in September I966.

Dr. Jones has started the weekly Ward Conference at which the medical 
social worker, the disablement resettlement officer, the physiotherapists, occupational therapists and resident medical staff attached to the unit attend. He has been instrumental in forging a very close link with the Department of Social Science and the Athletic Department at the University of Keele. He has a special interest in the various mechanical aids for the severely disabled. I hope that in the near future he will set out some of these innovations in a communication to this Society.

The urological side of the unit is under the care of Mr. D. St. Clair Henderson, F.R.C.S., whose interest in the paralysed bladder extends over 15 years. At the present time, for administrative reasons, he is obliged to transfer the more complicated cases to his own unit at Dudley Road Hospital, Birmingham. I think it is only right to say that we regard this as a serious deficiency in the service and that no one is more anxious to rectify this than Mr. Henderson. Considering the superb talent available, it is unfortunate that we cannot offer our urologist the required facilities. However, recognising the problem no doubt will help us to solve it all the sooner.

Similar remarks apply in the field of general surgery, where we are offered a magnificent service by Mr. Russell Johnson, F.R.C.S., and his colleagues at the Royal Salop Infirmary. But here again the principle of 'nursing the patient on the unit' is sometimes broken.

The pathological service covers most of our everyday needs. An immediate bacteriological and biochemical service would be a distinct advantage, and we hope to provide such an arrangement before the end of the year.

The plastic work is in the capable hands of Mr. Oliver Mansfield, F.R.C.S.

It has been our policy to accept a certain number of non-traumatic cases. I believe this is salutory for both patients and staff.

\section{TABLE}

Spinal Injuries

I January I964 to 30 June 1967

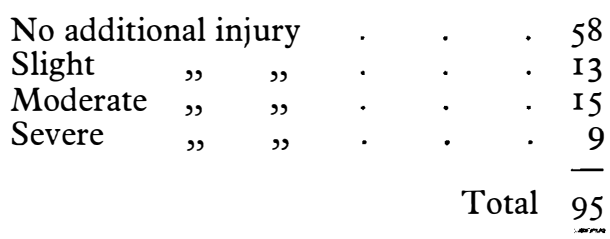

Like other units we have an accommodation problem, made no easier by the increasing number of review cases and the difficulty in resettling the tetraplegics.

We recognise other structural deficiencies, soon I hope to be rectified. We lack pre-discharge accommodation and, perhaps more importantly with the increasing number of tetraplegics, we need hostel accommodation. We look with envious eyes at the hostel recently built at Stoke Mandeville, and are considering ways and means towards a similar unit at Oswestry. For those who are employable in office or factory and who cannot be looked after in their own homes- 
here I am thinking in particular of the young tetraplegics-we would like to see hostel accommodation with Oswestry-trained staff near the larger industrial centres. But this is a national problem no less urgent than any other I can think of in the Health Service.

On the teaching side we feel we have made some contribution. The registrars accepted for training at Oswestry have completed their training in general surgery and are in possession of a fellowship. We normally expect a registrar to work three months on the unit during his two-year term of Office. With I4 registrars to accommodate, this is not always possible, but we feel that those unlucky enough to miss secondment have ample opportunity to visit the wards-to attend the weekly case conferences, and to take an active part in the monthly Clinical Conference. In addition, we offer a number of supernumerary Senior House Officer appointments to overseas graduates dedicated to orthopaedic surgery.

We arrange instruction for post-graduates of Liverpool University who are reading for the Mastership in Orthopaedic Surgery, and for the undergraduates of Birmingham and Manchester Universities. On the nursing side we hope shortly to introduce a three-monthly course in paraplegic nursing.

Pure research on the unit has gone on in a desultory fashion but with better facilities we hope to rectify this. Clinical research, on the other hand, has not been neglected and I would like to mention in particular the published work of Beatson (1963), Elson (1965) and Roaf (1966).

In conclusion, I would like to say that there is a very real problem in finding the ideal site for a spinal injury unit. If patients are to be admitted directly after the accident, and with associated injuries, the facilities afforded by structural attachment, or close proximity to a large general hospital, are essential. Unfortunately I know of very few hospitals in this country where the structural alterations and ancillary services could be made available in a reasonable time.

While there are disadvantages in siting such a unit in a specialised hospital, there is much to be said for the facilities offered by a well-established orthopaedic hospital.

I believe the man in charge of the unit should have no other clinical commitments.

Perhaps more important than the bricks and mortar is the experience, the spirit of dedication, the adaptability, and the goodwill of all concerned.

\section{REFERENCES}

Beatson, T. R. (1963). F. Bone E ft. Surg. 45-B, 2 I.

Elson, R. (1965). Practical Management of Spinal Injuries for Nurses. Edinburgh: Livingstone.

Griffiths, D. Ll., Seddon, H. J. \& Roaf, R. (i956). Pott's Paraplegia. London: Oxford University Press.

RoAf, R. (I966). Scoliosis. Edinburgh: Livingstone. 